\title{
ДВУМЕРНАЯ МОДЕЛЬ ПРОЦЕССА ГАЗИФИКАЦИИ ТВЕРДОГО ТОПЛИВА В НЕПОДВИЖНОМ СЛОЕ ПОД ДАВЛЕНИЕМ. \\ 1. ИССЛЕДОВАНИЕ КОНВЕРСИИ ШУБАРКОЛЬСКОГО КАМЕННОГО УГЛЯ В ПАРОКИСЛОРОДНОЙ СМЕСИ ПРИ ОТНОШЕНИИ МАССОВЫХ ДОЛЕЙ $\mathrm{H}_{2} \mathrm{O} / \mathrm{O}_{2}=45 / 55$
}

\author{
Б.Б. Рохман, докт. техн. наук \\ Институт угольных энерготехнологий НАН Украины, \\ 04070, г. Киев, ул. Андреевская 19.
}

\begin{abstract}
Построена нестационарная модель процесса парокислородной газификации твердого топлива в фиксированном слое под давлением с учетом межфазного конвективного теплообмена, радиационно-кондуктивного теплопереноса твердой фазы, лучистого и кондуктивного теплообмена слоя со стенкой реактора, гетерогенных и гомогенных химических реакиий, сил тяжести и аэродинамического сопротивления.

Модель позволяет получить детальную информацию о распределении температур фаз, диаметра угольных частии, концентраџий газовых компонентов по высоте слоя в зависимости от времени при газификации шубаркольского каменного длиннопламенного угля под давлением 3 Мпа при отношении массовых долей в парокислородной смеси Н2O/O2 = 45/55. Полученная информация может быть использована при конструировании реакторов, пуско-наладочных режимах и работе газогенератора на различных нагрузках, когда процесс парокислородной газификации угля является нестационарным из-за ичиклчности подачи исходного топлива и выгрузки золы при помощи использование системы шлюзовых бункеров. Показано, что участок окислительной зоны, где температура угольных частии достигает максимального значения, очень узок и составляет 10-11 мм. Предложены два альтернативных режима работы газогенератора. Первый из них Н2O/O2 = 40/60 связан с повымением максимальной температуры частии в области, прилегающей $\kappa$ поду реактора до $1550{ }^{\circ} \mathrm{C}$, что позволяет организовать устойчивое жидкое шлакоудаление из газогенератора. Второй режим $\mathrm{H}_{2} \mathrm{O} / \mathrm{O}_{2}=$ 72/28 основан на твердом шлакоудалении, когда температура частии не превымает 1000 ㄷ. Библ.11, табл.1, рис.9.
\end{abstract}

Ключевые слова: неподвижный слой, уголь, теплопроводность, парокислородная газификация, температура.

\section{TWO-DIMENSIONAL MODEL OF THE SOLID FUEL GASIFICATION IN A FIXED BED UNDER PRESSER.}

\section{INVESTIGATION OF SHUBARKOL COAL CONVERSION IN A STEAM-OXYGEN} MIXTURE WITH THE MASS PART OF $\mathrm{H}_{2} \mathrm{O}_{/} \mathrm{O}_{2}=45 / 55$

\author{
B.B. Rokhman, doctor of technical sciences, \\ Coal Energy Technology Institute NAS of Ukraine, \\ 04070, Kyiv, str. Andreevskaya 19
}

A non-stationary model of the steam-oxygen gasification of solid fuel in a fixed bed under pressure has been developed with allowance for the interphase convective heat exchange, radiation-conductive heat transfer of the solid phase, radiant and conductive heat exchange of the bed with the reactor wall, heterogeneous and homogeneous chemical reactions, gravity and aerodynamic resistance. Temperature distribution of the phases, diameter of the coal particles, concentrations of the gas components over the bed height as a function of time during the gasification of Shubarkol long-flame coal under a pressure of 3 MPa at a ratio of mass fractions in the oxygen-oxygen mixture $\mathrm{H}_{2} \mathrm{O} / \mathrm{O}_{2}=45 / 55$ is obtained. The obtained information can be used in the design of reactors, commissioning modes and the gas generator operation at various loads, when the process of steam-oxygen coal gasification is nonstationary due to the cyclical fuel supply and ash discharge by using a system of lock bins. It has been shown that the section of the oxidizing zone, where the temperature of the coal particles reaches its maximum value, is very narrow and is 10-11 mm. Two alternative modes of the gas generator operation are proposed. The first mode $\mathrm{H}_{2} \mathrm{O} / \mathrm{O}_{2}=40 / 60$ is associated with an increase in the maximum temperature of the particles in a small area adjacent to the reactor bottom from to $1550{ }^{\circ} \mathrm{C}$, which makes it possible to organize stable liquid slag removal from the gas generator. The second mode $\mathrm{H}_{2} \mathrm{O} / \mathrm{O}_{2}=72 / 28$ is based on solid slag removal, when the temperature of the particles does not exceed $1000{ }^{\circ} \mathrm{C}$. Referenses 11, tabl. 1, fig. 9.

Keywords: fixed bed, coal, thermal conductivity, steam-oxygen gasification, temperature. 


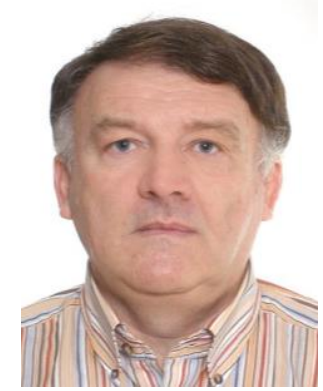

Б.Б. Рохман

B. Rokhman
Сведения об авторе: ведущий научный сотрудник Института угольных энерготехнологий НАН Украины, доктор технических наук. Биографические данные Рохмана Б.Б. размещены в известных мировых изданиях "Who's Who in Science and Engineering" и "2000 Outstanding Intellectuals of the 21st Century".

Образование: Новочеркасский политехнический институт.

Научная сфера: Математическое моделирование аэродинамики, тепломассообмена и химического реагирования полидисперсного ансамбля твердого топлива в камерных и слоевых топках, в реакторах с циркулирующим кипящим слоем и в кипящем слое.

Публикации: более 90 научных работ, из них 27 работ содержатся в наукометрической базе Scopus и 4 в наукометрической базе $\mathrm{Web}$ of Science.

ORCID: 0000-0002-1270-6102

Контакты: тел.: +38-044-425-53-77

e-mail: Brolene@yahoo.com
Author information: the leading researcher of the Institute of Coal Energy Technologies of the NAS of Ukraine, Doctor of Technical Sciences. Biographical information of Rohman B.B. is published in well-known world directories "Who's Who in Science and Engineering" and "2000 Outstanding Intellectuals of the 21 st Century".

Education: Novocherkassk Polytechnic Institute.

Research area: Mathematical modeling of aerodynamics, heat and mass transfer and chemical reaction of a polydisperse ensemble of solid fuel in chamber and layer furnaces, in reactors with a circulating fluidized bed and in the fluidized bed.

Publications: more than 90 scientific papers, 27 of them are contained in the science-based Scopus database and 4 in the science-based Web of Science database.

ORCID: 0000-0002-1270-6102

Contacts: phone: $+38-044-425-53-77$

e-mail: Brolene@yahoo.com

\section{Условные обозначения:}

a - степень черноты частицы;

$A, N, O, \quad$ - массовые доли золы, азота, кислорода, серы, $S, V, W$ летучих веществ и влаги в твердом топливе;

$B \quad$ - расход, кг/ч;

$C \quad-$ концентрация газовых компонентов, (кмоль/ $\mathrm{M}^{3}$ ) или массовая доля углерода в твердом топливе ;

c $\quad$ - теплоемкость, кДж/(кг·К);

$D \quad$ - коэффициент диффузии, $\mathrm{m}^{2} / \mathrm{c}$;

$H$ - высота (м) или массовая доля водорода;

$h \quad-$ коэффициент теплообмена между слоем и частицей, кДж/(c· $\left.\mathrm{m}^{2} \cdot \mathrm{K}\right)$;

$g \quad-$ ускорение свободного падения, м/ $/ \mathrm{c}^{2} ;$

$k-$ константа скорости реакции, м/с;

$L \quad$ - универсальная газовая постоянная кДж/(кмоль К К);

$m \quad-$ масса, кг;

$\mathrm{Nu} \quad$ - критерий Нуссельта;

$P \quad$ - давление, $\mathrm{H} / \mathrm{M}^{2}$;

$Q \quad$ - тепловой эффект реакции (кДж/кмоль) или тепловой поток (кДж/(c· $\left.\left.\mathrm{M}^{3}\right)\right)$;

Индексы нижние:

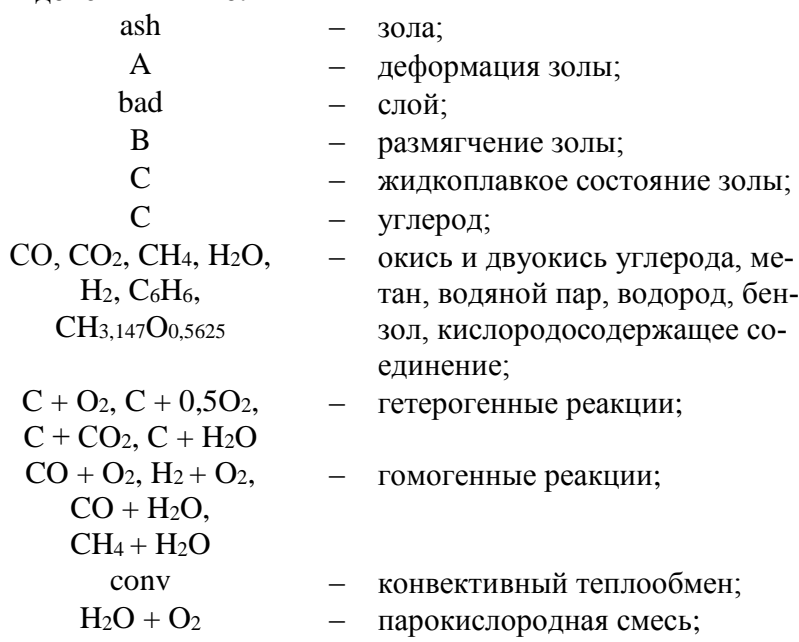

$R \quad$ - объемная доля компонента газовой смеси;

- кмоль $/\left(\mathrm{M}^{3} \cdot \mathrm{c}\right)$; скорость гомогенной реакции

- температура, ${ }^{\circ} \mathrm{C}$;

- температура, K;

- скорость, м/с;

- аксиальная координата, м;

- коэффициент массообмена, м/с;

- диаметр частицы, м;

$\varepsilon \quad$ - порозность слоя;

$\lambda$ - коэффициент теплопроводности, кДж/(c· $\mathbf{M} \cdot \mathrm{K})$;

$\eta \quad$ - кинематическая вязкость, $\mathrm{m}^{2} / \mathrm{c}$;

- молекулярная масса, кг/кмоль;

- плотность, кг $/ \mathrm{M}^{3}$;

- время, с;

- параметр модели теплопроводности зернистого слоя.

$\mathrm{CO}_{2} \rightarrow \mathrm{cm}, \mathrm{O}_{2} \rightarrow \mathrm{cm}, \quad-$ диффузия углекислого газа, кис$\mathrm{CO} \rightarrow \mathrm{cm}, \mathrm{H}_{2} \mathrm{O} \rightarrow \mathrm{cm}$, лорода, окиси углерода, водяно$\mathrm{H}_{2} \rightarrow \mathrm{cm}, \mathrm{C}_{6} \mathrm{H}_{6} \rightarrow \mathrm{cm}, \quad$ го пара, водорода, бензола, ме$\mathrm{CH}_{4} \rightarrow \mathrm{CM}$,

$\mathrm{CH}_{3,147} \mathrm{O}_{0,5625} \rightarrow \mathrm{cm}$

$\mathrm{D}$ - диффузия; тана и кислородосодержащего соединения в газовую смесь;

d — - сухая масса;

g $\quad-$ газ;

$\max \quad-$ максимальное значение;

p $\quad-$ частица;

$\mathrm{p} \rightarrow \mathrm{W} \quad$ - передача тепла от частиц к стен-

slag - - шлак;

volat $\quad-$ летучие вещества;

ф - - фиксированный углерод;

эф - - эффективный;

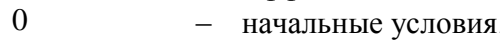




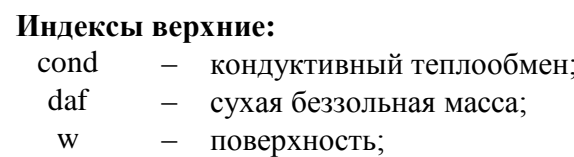

Введение. В последние годы одной из приоритетных задач промышленности и энергетики является сокращение потребления дорогостоящего природного газа, использование которого делает нерентабельным металлургическую промышленность, производство различных химических продуктов на основе природного газа, например, аммиака, метанола, уксусной кислоты и т. д. Для сокращения потребления объемов газа необходимо широко внедрять газозамещающие технологии, такие, например, как использование твердых топлив (уголь, биоэнергетические ресурсы) в доменных печах и энергетических установках для производства генераторного газа. Одной из таких технологий термохимической переработки твердого топлива является парокислородная газификация дробленного угля в неподвижном слое под давлением в газогенераторах типа Lurgi (SEDIN), BGL.

Настоящая статья посвящена моделированию и теоретическому исследованию нестационарного процесса парокислородной газификации частиц шубаркольского каменного длиннопламенного угля под давлением 3 МПа в неподвижном слое $\left(C_{\phi}^{\mathrm{r}}=43,48 \%, C_{\text {volat }}^{\mathrm{r}}=15,698 \%, S^{\mathrm{r}}=\right.$ $=0,746 \%, H^{\mathrm{r}}=4,117 \%, O^{\mathrm{r}}=11,773 \%, N^{\mathrm{r}}=$ $=1,139 \%, W^{\mathrm{r}}=14,5 \%, A^{\mathrm{r}}=8,55 \%, V^{\mathrm{daf}}=43,5 \%$, $\left.t_{\mathrm{A}}=1100^{\circ} \mathrm{C}, t_{\mathrm{B}}=1420^{\circ} \mathrm{C}, t_{\mathrm{C}}=1440^{\circ} \mathrm{C}\right)$. В отличие от стационарного процесса, где распределение физико-химических параметров дискретной и газовой фаз в слое не зависит от времени из-за равенства скоростей подачи и термохимической переработки дробленного топлива, здесь рассматривается случай одноразовой (невозобновляемой) загрузки исходного угля на колосниковую решетку. При такой постановке задачи процесс газификации является неустановившимся и характеризуется изменяющимися во времени профилями температур и концентраций двухфазной среды в слое.

В соответствии с изменениями, претерпеваемыми топливом на различных стадиях термохимической переработки, неподвижный слой угля в реакторе можно условно разделить на четыре зоны (рис. 1). Первая из них (поз. 2), примыкающая к колосниковой решетке, формируется из частиц золы и шлака, образующихся за счет горения и газификации исходного угля. Этот слой играет роль засыпки, выравнивающей распределение парокислородного дутья (поз. 1), и защищает колосники от перегрева. Над шлаковой подушкой $\operatorname{rad}$

r

- лучистый теплообмен;

- рабочая масса.

располагается окислительная зона (поз. 3), где практически весь кислород на очень небольшом участке слоя расходуется на конверсию углерода и догорание продуктов газификации $\mathrm{CO}$ и $\mathrm{H}_{2}$.

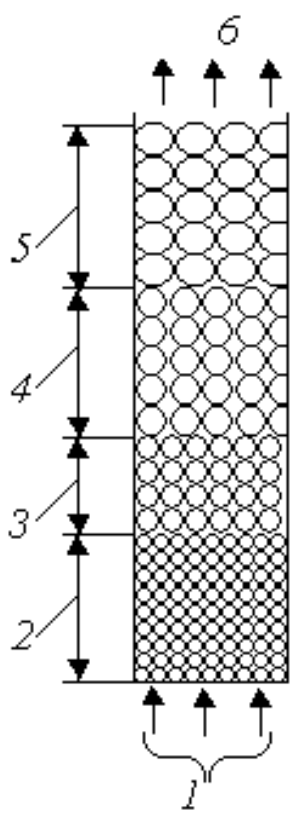

Эта область характеризуется максимальным уровнем температур из-за высоких значений тепловыделений гетерогенных и гомогенных химических реакций. В восстановительной зоне (поз. 4) газовые компоненты $\mathrm{CO}_{2}$ и $\mathrm{H}_{2} \mathrm{O}$ вступают в реакцию с углеродом с образованием горючих веществ $\mathrm{CO}$ и $\mathrm{H}_{2}$. Указанная область имеет значительно большую протяженность и более низкий уровень температур по сравнению с окислительной зоной за счет протекания в ней эндотермических восстановительных реакций с высокими значениями энергии активации. В четвертой зоне (поз. 5) высушенные дробленные частицы угля нагреваются бескислородной газовой смесью за счет межфазного конвективного теплообмена и радиационнокондуктивного теплопереноса твердой фазы, что обеспечивает выход из дробленки летучих веществ, которые смешиваются с газовой средой, выходящей из третьей зоны, тем самым формируя генераторный газ на выходе из установки.

Постановка задачи. Предлагаемая модель базируется на следующих основных предпосылках: 1) процесс нестационарный; 2) газовая смесь в реакторе состоит из кислорода, диоксида и оксида углерода, метана, водяного пара, водорода и бензола; 3) дисперсная фаза включает монодисперсные частицы сферической формы; 4) выход летучих и протекание гетерогенных реакций го- 
рения и газификации на поверхности угольных частиц приводит к уменышению их размера; 5) усадка неподвижного слоя за счет термохимической переработки твердого топлива не учитывается; 6) газ движется в режиме идеального вытеснения; 7) стехиометрическая схема реакций включает в себя четыре гетерогенные реакции:

$$
\begin{gathered}
\mathrm{C}+\mathrm{O}_{2}=\mathrm{CO}_{2}, \mathrm{C}+0,5 \mathrm{O}_{2}=\mathrm{CO}, \mathrm{C}+\mathrm{CO}_{2}= \\
=2 \mathrm{CO} \text { и } \mathrm{C}+\mathrm{H}_{2} \mathrm{O}=\mathrm{CO}+\mathrm{H}_{2} .
\end{gathered}
$$

и пять гомогенных:

$$
\begin{gathered}
\mathrm{CH}_{3,147} \mathrm{O}_{0,5625} \rightarrow 0,09132 \mathrm{CO}+0,0581 \mathrm{CO}_{2}+ \\
+0,5042 \mathrm{CH}_{4}+0,05783 \mathrm{C}_{6} \mathrm{H}_{6}+ \\
+0,03655 \mathrm{H}_{2}+0,3549 \mathrm{H}_{2} \mathrm{O} \\
\mathrm{CO}+0,5 \mathrm{O}_{2}=\mathrm{CO}_{2}, \mathrm{H}_{2}+0,5 \mathrm{O}_{2}= \\
=\mathrm{H}_{2} \mathrm{O}, \mathrm{CO}+\mathrm{H}_{2} \mathrm{O}=\mathrm{CO}_{2}+\mathrm{H}_{2} \\
\text { и } \mathrm{CH}_{4}+\mathrm{H}_{2} \mathrm{O}=\mathrm{CO}+3 \mathrm{H}_{2} .
\end{gathered}
$$

В стехиометрической схеме реакций летучие шубаркольского каменного длиннопламенного угля представлены формулой кислородосодержащего соединения $\mathrm{CH}_{3,147} \mathrm{O}_{0,5625}$, которое при нагреве разлагается на газовые компоненты $\mathrm{CO}, \mathrm{CO}_{2}$, $\mathrm{CH}_{4}, \mathrm{C}_{6} \mathrm{H}_{6}, \mathrm{H}_{2}$ и $\mathrm{H}_{2} \mathrm{O}$ согласно первой реакции (2).

Слой прогревается высокотемпературной смесью дымовых газов и воздуха до температуры воспламенения частиц в узкой области, примыкающей к решетке. Далее происходит отключение теплоносителя и подача вместо него парокислородной смеси с температурой $t_{\mathrm{H}_{2} \mathrm{O}+\mathrm{O}_{2}}=$ $450^{\circ} \mathrm{C}$. За начало отсчета $\tau=0$ выбрано время воспламенения твердой фазы.

Основные уравнения. Система уравнений, описывающая аэродинамику, тепломассообмен и химическое реагирование дробленных частиц и газовой фазы в плотном слое газификатора, может быть представлена в следующем виде.

Уравнение неразрывности для кислорода

$$
\begin{aligned}
\frac{\partial C_{\mathrm{O}_{2}}}{\partial \tau}+\frac{\partial\left(u_{\mathrm{g}} C_{\mathrm{O}_{2}}\right)}{\partial z}=\frac{\partial}{\partial z}[ & {\left[D_{\mathrm{O}_{2} \rightarrow \mathrm{cm}} \frac{\partial C_{\mathrm{O}_{2}}}{\partial z}\right]-\frac{6\left(k_{\mathrm{C}+\mathrm{O}_{2}}+k_{\mathrm{C}+0.5 \mathrm{O}_{2}}\right) C_{\mathrm{O}_{2}}^{\mathrm{w}}(1-\varepsilon)}{\delta}-} \\
& -0,5 r_{\mathrm{CO}+\mathrm{O}_{2}}-0,5 r_{\mathrm{H}_{2}+\mathrm{O}_{2}} .
\end{aligned}
$$

Уравнение неразрывности для диоксида углерода

$$
\begin{aligned}
& \frac{\partial C_{\mathrm{CO}_{2}}}{\partial \tau}+\frac{\partial\left(u_{\mathrm{g}} C_{\mathrm{CO}_{2}}\right)}{\partial z}=\frac{\partial}{\partial z}\left[D_{\mathrm{CO}_{2} \rightarrow \mathrm{cm}} \frac{\partial C_{\mathrm{CO}_{2}}}{\partial z}\right]+\frac{6\left(k_{\mathrm{C}+\mathrm{O}_{2}} C_{\mathrm{O}_{2}}-k_{\mathrm{C}+\mathrm{CO}_{2}} C_{\mathrm{CO}_{2}}^{\mathrm{w}}\right)(1-\varepsilon)}{\delta}+r_{\mathrm{CO}+\mathrm{O}_{2}}+ \\
& +r_{\mathrm{CO}+\mathrm{H}_{2} \mathrm{O}}+0,0581 r_{\mathrm{CH}_{3,147} \mathrm{O}_{0.525} \rightarrow} \text {. }
\end{aligned}
$$

Уравнение неразрывности для окиси углерода

$$
\begin{aligned}
\frac{\partial C_{\mathrm{CO}}}{\partial \tau}+\frac{\partial\left(u_{\mathrm{g}} C_{\mathrm{CO}}\right)}{\partial z}=\frac{\partial}{\partial z} & {\left[D_{\mathrm{CO} \rightarrow \mathrm{cm}} \frac{\partial C_{\mathrm{CO}}}{\partial z}\right]+\frac{6\left[2\left(k_{\mathrm{C}+0.5 \mathrm{O}_{2}} C_{\mathrm{O}_{2}}^{\mathrm{w}}+k_{\mathrm{C}_{+} \mathrm{CO}_{2}} C_{\mathrm{CO}_{2}}^{\mathrm{w}}\right)+k_{\mathrm{C}+\mathrm{H}_{2} \mathrm{O}} C_{\mathrm{H}_{2} \mathrm{O}}^{\mathrm{w}}\right](1-\varepsilon)}{\delta}-} \\
& -r_{\mathrm{CO}+\mathrm{O}_{2}}-r_{\mathrm{CO}+\mathrm{H}_{2} \mathrm{O}}+r_{\mathrm{CH}_{4}+\mathrm{H}_{2} \mathrm{O}}+0.09132 r_{\mathrm{CH}_{3,14} \mathrm{O}_{0,5625} \rightarrow}
\end{aligned}
$$

Уравнение неразрывности для метана

$$
\frac{\partial C_{\mathrm{CH}_{4}}}{\partial \tau}+\frac{\partial\left(u_{\mathrm{g}} C_{\mathrm{CH}_{4}}\right)}{\partial z}=\frac{\partial}{\partial z}\left[D_{\mathrm{CH}_{4} \rightarrow \mathrm{cm}} \frac{\partial C_{\mathrm{CH}_{4}}}{\partial z}\right]-r_{\mathrm{CH}_{4}+\mathrm{H}_{2} \mathrm{O}}+0,5042 r_{C_{3,14} O_{0,5625} \rightarrow} .
$$

Уравнение неразрывности для водяного пара

$$
\begin{aligned}
& \frac{\partial C_{\mathrm{H}_{2} \mathrm{O}}}{\partial \tau}+\frac{\partial\left(u_{\mathrm{g}} C_{\mathrm{H}_{2} \mathrm{O}}\right)}{\partial z}=\frac{\partial}{\partial z}\left[D_{\mathrm{H}_{2} \mathrm{O} \rightarrow \mathrm{cm}} \frac{\partial C_{\mathrm{H}_{2} \mathrm{O}}}{\partial z}\right]-\frac{6 k_{\mathrm{C}+\mathrm{H}_{2} \mathrm{O}} C_{\mathrm{H}_{2} \mathrm{O}}^{\mathrm{w}}(1-\varepsilon)}{\delta}+r_{\mathrm{H}_{2}+\mathrm{O}_{2}}-r_{\mathrm{CO}+\mathrm{H}_{2} \mathrm{O}}+ \\
& +0,3549 r_{\mathrm{CH}_{3,14} \mathrm{O} \mathrm{O}_{0,5625} \rightarrow} \text {. }
\end{aligned}
$$

Уравнение неразрывности для водорода

$$
\begin{gathered}
\frac{\partial C_{\mathrm{H}_{2}}}{\partial \tau}+\frac{\partial\left(u_{\mathrm{g}} C_{\mathrm{H}_{2}}\right)}{\partial z}=\frac{\partial}{\partial z}\left[D_{\mathrm{H}_{2} \rightarrow \mathrm{cm}} \frac{\partial C_{\mathrm{H}_{2}}}{\partial z}\right]+\frac{6 k_{{\mathrm{C}+\mathrm{H}_{2} \mathrm{O}}} C_{\mathrm{H}_{2} \mathrm{O}}^{\mathrm{w}}(1-\varepsilon)}{\delta}-r_{\mathrm{H}_{2}+\mathrm{O}_{2}}+r_{\mathrm{CO}+\mathrm{H}_{2} \mathrm{O}}+3 r_{\mathrm{CH}_{4}+\mathrm{H}_{2} \mathrm{O}}+ \\
+0,03655 r_{\mathrm{CH}_{3,4} \mathrm{O}_{0,5625} \rightarrow} \cdot
\end{gathered}
$$

Уравнение неразрывности для бензола 


$$
\frac{\partial C_{\mathrm{C}_{6} \mathrm{H}_{6}}}{\partial \tau}+\frac{\partial\left(u_{\mathrm{g}} C_{\mathrm{C}_{6} \mathrm{H}_{6}}\right)}{\partial z}=\frac{\partial}{\partial z}\left[D_{\mathrm{C}_{6} \mathrm{H}_{6} \rightarrow \mathrm{cm}} \frac{\partial C_{\mathrm{C}_{6} \mathrm{H}_{6}}}{\partial z}\right]+0,05783 r_{\mathrm{CH}_{3,14} \mathrm{O}_{0,5625} \rightarrow} \cdot
$$

Уравнение неразрывности для кислородосодержащего соединения $\mathrm{CH}_{3,147} \mathrm{O}_{0,5625}$

$$
\begin{aligned}
& \frac{\partial C_{\mathrm{CH}_{3,14} \mathrm{O}_{0,5625}}}{\partial \tau}+\frac{\partial\left(u_{\mathrm{g}} C_{\mathrm{CH}_{3,14} \mathrm{O}_{0,5625}}\right)}{\partial z}=\frac{6(1-\varepsilon) m_{\mathrm{p} 0}\left(1-V_{\mathrm{d}}\right) V_{\mathrm{d}} A_{\mathrm{volat}} \exp \left[-\int_{0}^{\tau} A_{\mathrm{volat}} d \tau\right]}{\pi\left(1-V_{\mathrm{d}} \exp \left[-\int_{0}^{\tau} A_{\mathrm{volat}} d \tau\right]\right)^{2} \delta^{3} \mu_{\mathrm{CH}_{3,14} \mathrm{O}_{0,5625}}}+ \\
& +\frac{\partial}{\partial z}\left[D_{\mathrm{CH}_{3,14} \mathrm{O}_{0,5625} \rightarrow \mathrm{cm}} \frac{\partial C_{\mathrm{CH}_{3,14} \mathrm{O}_{0,5625}}}{\partial z}\right]-r_{\mathrm{CH}_{3,14} \mathrm{O}_{0,5625} \hookrightarrow} \cdot
\end{aligned}
$$

Уравнение изменения диаметра частиц

$$
\begin{gathered}
\frac{d \delta}{d \tau}=-\frac{\delta_{0}^{3}\left(1-V_{\mathrm{d}}\right) V_{\mathrm{d}} A_{\text {volat }} \exp \left[-\int_{0}^{\tau} A_{\text {volat }} d \tau\right]}{3 \delta^{2}\left(1-V_{\mathrm{d}} \exp \left[-\int_{0}^{\tau} A_{\text {volat }} d \tau\right]\right)^{2}}- \\
-\left[\left(k_{\mathrm{C}+\mathrm{O}_{2}}+2 k_{\mathrm{C}+0.5 \mathrm{O}_{2}}\right) C_{\mathrm{O}_{2}}^{\mathrm{w}}+k_{{\mathrm{C}+\mathrm{CO}_{2}}} C_{\mathrm{CO}_{2}}^{\mathrm{w}}+k_{\mathrm{C}^{+} \mathrm{H}_{2} \mathrm{O}} C_{\mathrm{H}_{2} \mathrm{O}}^{\mathrm{w}}\right] \frac{2 \mu_{\mathrm{C}}}{\rho_{\mathrm{p}}} .
\end{gathered}
$$

Уравнение сохранения количества движения газовой фазы

$$
\begin{aligned}
\frac{\partial\left(\rho_{\mathrm{g}} u_{\mathrm{g}}\right)}{\partial \tau}+\frac{\partial\left(\rho_{\mathrm{g}} u_{\mathrm{g}}^{2}\right)}{\partial z}=-\frac{\partial P_{\mathrm{g}}}{\partial z}-g \rho_{\mathrm{g}} & +\frac{\partial}{\partial z}\left[\rho_{\mathrm{g}} \eta_{\mathrm{g}} \frac{\partial u_{\mathrm{g}}}{\partial z}\right]-\frac{150 \eta_{\mathrm{g}} \rho_{\mathrm{g}}(1-\varepsilon)^{2} u_{\mathrm{g}}}{\delta^{2} \varepsilon^{3}}- \\
& -\frac{1,75 \rho_{\mathrm{g}}(1-\varepsilon) u_{\mathrm{g}}^{2}}{\delta \varepsilon^{3}} .
\end{aligned}
$$

Уравнение теплового баланса частиц

$$
\begin{aligned}
\rho_{\mathrm{p}}(1-\varepsilon) \frac{\partial c_{\mathrm{p}} t_{\mathrm{p}}}{\partial \tau}= & \frac{\partial}{\partial z}\left[\lambda_{\text {эф }} \frac{\partial t_{\mathrm{p}}}{\partial z}\right]+\left[\left(k_{\mathrm{C}+\mathrm{O}_{2}} Q_{\mathrm{C}+\mathrm{O}_{2}}+k_{\mathrm{C}+0,5 \mathrm{O}_{2}} Q_{\mathrm{C}+0,5 \mathrm{O}_{2}}\right) C_{\mathrm{O}_{2}}^{\mathrm{w}}-k_{{\mathrm{C}+\mathrm{CO}_{2}} C_{\mathrm{CO}_{2}}^{\mathrm{w}} Q_{\mathrm{C} \mathrm{CO}_{2}}-}\right. \\
& \left.-k_{\mathrm{C}+\mathrm{H}_{2} \mathrm{O}} C_{\mathrm{H}_{2} \mathrm{O}}^{\mathrm{w}} Q_{\mathrm{C}+\mathrm{H}_{2} \mathrm{O}}-h_{\text {conv }}\left(t_{\mathrm{p}}-t_{\mathrm{g}}\right)\right] \frac{6(1-\varepsilon)}{\delta}-Q_{\mathrm{p} \rightarrow \mathrm{w}}^{\mathrm{rad}}-Q_{\mathrm{p} \rightarrow \mathrm{w}}^{\mathrm{cond}} .
\end{aligned}
$$

Уравнение сохранения энергии несущей среды

$$
\begin{aligned}
& \frac{\partial \rho_{\mathrm{g}} c_{\mathrm{g}} t_{\mathrm{g}}}{\partial \tau}+\frac{\partial\left(\rho_{\mathrm{g}} u_{\mathrm{g}} c_{\mathrm{g}} t_{\mathrm{g}}\right)}{\partial z}=\frac{\partial}{\partial z}\left[\lambda_{\mathrm{g}, \mathrm{g}} \frac{\partial t_{\mathrm{g}}}{\partial z}\right]+h_{\mathrm{conv}}\left(t_{\mathrm{p}}-t_{\mathrm{g}}\right) \frac{6(1-\varepsilon)}{\delta}+ \\
& +r_{\mathrm{CO}+\mathrm{O}_{2}} Q_{\mathrm{CO}+\mathrm{O}_{2}}+r_{\mathrm{H}_{2}+\mathrm{O}_{2}} Q_{\mathrm{H}_{2}+\mathrm{O}_{2}}+r_{\mathrm{CO}+\mathrm{H}_{2} \mathrm{O}} Q_{\mathrm{CO}+\mathrm{H}_{2} \mathrm{O}}+r_{\mathrm{CH}_{4}+\mathrm{H}_{2} \mathrm{O}} Q_{\mathrm{CH}_{4}+\mathrm{H}_{2} \mathrm{O}},
\end{aligned}
$$

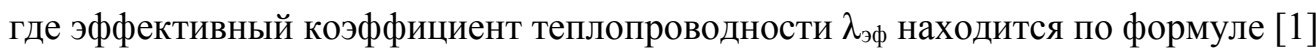

$$
\frac{\lambda_{\text {эФ }}}{\lambda_{\mathrm{g}}}=\varepsilon\left(1+\frac{\alpha_{\mathrm{rad}, \mathrm{g}} \delta}{\lambda_{\mathrm{g}}}\right)+\frac{1-\varepsilon}{1 / \Phi+\frac{\alpha_{\mathrm{rad}, \mathrm{p}} \delta}{\lambda_{\mathrm{g}}}}+\frac{2 \lambda_{\mathrm{g}}}{3 \lambda_{\mathrm{p}}} .
$$

Коэффициент теплоотдачи излучением от частицы через газ мимо соседних зерен определяется согласно выражению [1]

$$
\alpha_{\mathrm{rad}, \mathrm{g}}=0,227 \cdot 10^{-9}\left[\frac{1}{1+\varepsilon\left(1-a_{\mathrm{p}}\right) /\left(2 a_{\mathrm{p}}(1-\varepsilon)\right)}\right]\left(t_{\mathrm{p}}+273\right)^{3},
$$


коэффициент теплоотдачи излучением между соседними частицами [1]

$$
\alpha_{\text {rad, } \mathrm{p}}=0,227 \cdot 10^{-9} \frac{a_{\mathrm{p}}\left(t_{\mathrm{p}}+273\right)^{3}}{2-a_{\mathrm{p}}},
$$

концентрации газовых компонентов на поверхности частицы и коэффициенты массообмена находятся согласно [2]

$$
\begin{gathered}
C_{\mathrm{O}_{2}}^{\mathrm{w}}=\frac{\alpha_{\mathrm{D}, \mathrm{O}_{2}} C_{\mathrm{O}_{2}}}{\alpha_{\mathrm{D}, \mathrm{O}_{2}}+k_{\mathrm{C}+\mathrm{O}_{2}}+k_{\mathrm{C}+0,5 \mathrm{O}_{2}}}, C_{\mathrm{CO}_{2}}^{\mathrm{w}}=\frac{\alpha_{\mathrm{D}, \mathrm{CO}_{2}} C_{\mathrm{CO}_{2}}+k_{{\mathrm{C}+\mathrm{O}_{2}} C_{\mathrm{O}_{2}}}^{\mathrm{w}}}{\alpha_{\mathrm{D}, \mathrm{CO}_{2}}+k_{\mathrm{C}+\mathrm{CO}_{2}}}, C_{\mathrm{H}_{2} \mathrm{O}}^{\mathrm{w}}=\frac{\alpha_{\mathrm{D}, \mathrm{H}_{2} \mathrm{O}} C_{\mathrm{H}_{2} \mathrm{O}}}{\alpha_{\mathrm{D}, \mathrm{H}_{2} \mathrm{O}}+k_{\mathrm{C}+\mathrm{H}_{2} \mathrm{O}}}, \\
C_{\mathrm{CO}}^{\mathrm{w}}=\frac{\alpha_{\mathrm{D}, \mathrm{CO}} C_{\mathrm{CO}}+2\left(k_{{\mathrm{C}+0,5 \mathrm{O}_{2}}} C_{\mathrm{O}_{2}}^{\mathrm{w}}+k_{\mathrm{C}+\mathrm{CO}_{2}} C_{\mathrm{CO}_{2}}^{\mathrm{w}}\right)+k_{{\mathrm{C}+\mathrm{H}_{2} \mathrm{O}} C_{\mathrm{H}_{2} \mathrm{O}}}^{\mathrm{w}}}{\alpha_{\mathrm{D}, \mathrm{CO}}}, \alpha_{\mathrm{D}, \mathrm{O}_{2}}=\frac{D_{\mathrm{O}_{2} \rightarrow \mathrm{cm}} \mathrm{Nu}}{\delta}, \\
\alpha_{\mathrm{D}, \mathrm{CO}_{2}}=\frac{D_{\mathrm{CO}_{2} \rightarrow \mathrm{cm}} \mathrm{Nu}}{\delta}, \alpha_{\mathrm{D}, \mathrm{CO}}=\frac{D_{\mathrm{CO} \rightarrow \mathrm{cM}} \mathrm{Nu}}{\delta}, \alpha_{\mathrm{D}, \mathrm{H}_{2} \mathrm{O}}=\frac{D_{\mathrm{H}_{2} \mathrm{O} \rightarrow \mathrm{cm}} \mathrm{Nu}}{\delta} .
\end{gathered}
$$

Скорости реакций $r_{\mathrm{H}_{2}+\mathrm{O}_{2}}, r_{\mathrm{CO}+\mathrm{H}_{2} \mathrm{O}}, r_{\mathrm{CO}+\mathrm{O}_{2}}, r_{\mathrm{CH}_{4}+\mathrm{H}_{2} \mathrm{O}}, r_{\mathrm{CH}_{3,14} \mathrm{O}_{0,5625} \rightarrow}$ и выхода летучих веществ из

\begin{tabular}{|c|c|c|}
\hline Реакции & $\begin{array}{l}\text { Выражения для скоростей реакций, } \\
\text { кмоль } /\left(\mathrm{m}^{3} \cdot \mathrm{c}\right)\end{array}$ & $\begin{array}{l}\text { Лите- } \\
\text { ратура }\end{array}$ \\
\hline $\mathrm{CO}+0,5 \mathrm{O}_{2}=\mathrm{CO}_{2}$ & $r_{\mathrm{CO}+\mathrm{O}_{2}}=2,239 \cdot 10^{12} C_{\mathrm{CO}} C_{\mathrm{H}_{2} \mathrm{O}}^{0,5} C_{\mathrm{O}_{2}}^{0,25} \cdot \exp \left[-167,4 \cdot 10^{3} /\left(L_{\mathrm{g}} T_{\mathrm{g}}\right)\right]$ & [3] \\
\hline $\mathrm{H}_{2}+0,5 \mathrm{O}_{2}=\mathrm{H}_{2} \mathrm{O}$ & $r_{\mathrm{H}_{2}+\mathrm{O}_{2}}=6,8 \cdot 10^{15} T_{g}^{-1} C_{\mathrm{H}_{2}}^{0,25} C_{\mathrm{O}_{2}}^{1,5} \exp \left[-167 \cdot 10^{3} /\left(L_{\mathrm{g}} T_{\mathrm{g}}\right)\right]$ & [3] \\
\hline $\mathrm{CO}+\mathrm{H}_{2} \mathrm{O}=\mathrm{CO}_{2}+\mathrm{H}_{2}$ & $\begin{aligned} r_{\mathrm{CO}+\mathrm{H}_{2} \mathrm{O}} & =2,34 \cdot 10^{10} \exp \left[-288,3 \cdot 10^{3} /\left(L_{\mathrm{g}} T_{\mathrm{g}}\right)\right] C_{\mathrm{H}_{2} \mathrm{O}} C_{\mathrm{CO}}^{0,5}- \\
& 2,2 \cdot 10^{7} \exp \left[-190 \cdot 10^{3} /\left(L_{\mathrm{g}} T_{\mathrm{g}}\right)\right] C_{\mathrm{H}_{2}}^{0,5} C_{\mathrm{CO}_{2}}\end{aligned}$ & [4] \\
\hline $\begin{array}{c}\mathrm{CH}_{4}+\mathrm{H}_{2} \mathrm{O}=\mathrm{CO}+ \\
3 \mathrm{H}_{2}\end{array}$ & $\begin{array}{c}r_{\mathrm{CH}_{4}+\mathrm{H}_{2} \mathrm{O}}=8 \cdot 10^{7} C_{\mathrm{CH}_{4}}^{0,5} C_{\mathrm{H}_{2} \mathrm{O}} \exp \left[-251 \cdot 10^{3} /\left(L_{\mathrm{g}} T_{\mathrm{g}}\right)\right]- \\
5,12 \cdot 10^{-14} C_{\mathrm{CO} C_{\mathrm{H}_{2}}} \exp \left[-27,3 \cdot 10^{3} /\left(L_{\mathrm{g}} T_{\mathrm{g}}\right)\right]\end{array}$ & [5] \\
\hline $\begin{array}{c}\mathrm{CH}_{3,147} \mathrm{O}_{0,5625} \rightarrow \\
0,09132 \mathrm{CO}+ \\
0,0581 \mathrm{CO}_{2+} \\
0,5042 \mathrm{CH}_{4+} \\
0,05783 \mathrm{C}_{6} \mathrm{H}_{6+} \\
0,03655 \mathrm{H}_{2}+0,3549 \mathrm{H}_{2} \mathrm{O}\end{array}$ & $r_{\mathrm{CH}_{3,14} \mathrm{O}_{0,5625} \rightarrow}=4,26 \cdot 10^{6} \exp \left[-60 \cdot 10^{3} /\left(L_{\mathrm{g}} T_{\mathrm{g}}\right)\right] C_{\mathrm{CH}_{3,14} \mathrm{O}_{0,5625}}$ & [6] \\
\hline $\begin{array}{l}\text { Выход летучих ве- } \\
\text { ществ }\end{array}$ & $\frac{d V}{d \tau}=-A_{\text {volat }} V, A_{\text {volat }}=1$ & [7] \\
\hline
\end{tabular}
угля определяются из выражений, приведенных в табл. 1.

Таблица 1. Кинетика гомогенных реакций.

Table 1. Kinetics of homogeneous reactions.

Граничные условия на входе в слой $(z=0)$ для уравнений (3)-(14) находятся из выражений:

$$
\begin{gathered}
\frac{\partial t_{\mathrm{p}}}{\partial z}=C_{\mathrm{CO}_{2}}=C_{\mathrm{CO}}=C_{\mathrm{CH}_{4}}=C_{\mathrm{H}_{2}}=C_{\mathrm{C}_{6} \mathrm{H}_{6}}=C_{\mathrm{CH}_{3,14} \mathrm{O}_{0,5625}}=0, C_{\mathrm{O}_{2}}=C_{\mathrm{O}_{2} 0}, C_{\mathrm{H}_{2} \mathrm{O}}=C_{\mathrm{H}_{2} \mathrm{O} 0}, \\
\iota_{\Pi}=\tau_{\Pi 10} \sigma e_{\Pi}=e_{\mathrm{\Pi} 0} \sigma,
\end{gathered}
$$

а на выходе из слоя $\left(я=P_{\text {иув }}\right)$

$$
\begin{gathered}
\frac{\partial t_{\mathrm{p}}}{\partial z}=\frac{\partial t_{\mathrm{g}}}{\partial z}=\frac{\partial C_{\mathrm{O}_{2}}}{\partial z}=\frac{\partial C_{\mathrm{CO}_{2}}}{\partial z}=\frac{\partial C_{\mathrm{CO}}}{\partial z}=\frac{\partial C_{\mathrm{CH}_{4}}}{\partial z}=\frac{\partial C_{\mathrm{H}_{2} \mathrm{O}}}{\partial z}=0, \\
\frac{\partial C_{\mathrm{H}_{2}}}{\partial z}=\frac{\partial C_{\mathrm{C}_{6} \mathrm{H}_{6}}}{\partial z}=\frac{\partial C_{\mathrm{CH}_{3,14} \mathrm{O}_{0,5625}}}{\partial z}=\frac{\partial u_{\mathrm{g}}}{\partial z}=0 .
\end{gathered}
$$


Численные результаты расчетов. Рассмотрим рабочий процесс парокислородной газификации дробленных частиц шубаркольского каменного угля диаметром $\delta_{0}=9$ мм и плотностью $\rho_{\mathrm{p}}=1350 \kappa \mathrm{\kappa} / \mathrm{M}^{3}\left(B_{\mathrm{H}_{2} \mathrm{O}}=1750 \kappa \Gamma / \mathrm{\kappa}, B_{\mathrm{O}_{2}}=\right.$ $=2139$ кг/ч и $t_{\mathrm{H}_{2} \mathrm{O}+\mathrm{O}_{2}}=450{ }^{\circ} \mathrm{C}$ ) в реакторе с неподвижным слоем порозностью $\varepsilon=0,4$, высотой слоя 2,75 м и сечением $0,5 \mathrm{~m}^{2}$ под давлением $P_{\mathrm{g}}=$ 3 Мпа. Как отмечалось выше, окислительная зона, где объемное содержание $\mathrm{O}_{2}$ снижается с $40,75 \%$ до $1 \%$ (рис. 2 , кривая 2), располагается в очень узком интервале $0,151 \mathrm{~m}<<z<0,25$ м и упакована дробленными частицами, не содержащими летучие вещества, о чем свидетельствует рис. 2 в, кривая 2. Рассматриваемый диапазон можно разделить на два характерных участка. На первом из них $0,151 \mathrm{~m}<z<0,161$ м наблюдается интенсивная конверсия коксозольных частиц в парокислородной смеси за счет окислительных и восстановительных гетерогенных реакций (см. (1)) и догорание продуктов газификации $\mathrm{CO}$ и $\mathrm{H}_{2}$ согласно реакциям $\mathrm{CO}+0,5 \mathrm{O}_{2}=\mathrm{CO}_{2}$ и $\mathrm{H}_{2}+0,5 \mathrm{O}_{2}=\mathrm{H}_{2} \mathrm{O}$. Здесь тепловыделение экзотермических реакций превалирует над теплопоглощением эндотермических реакций, вследствие чего температура $t_{\mathrm{p}}$ возрастает с $450{ }^{\circ} \mathrm{C}$ до максимального значения $1365{ }^{\circ} \mathrm{C}$ (рис. 3 , кривая 2), объемные доли $\mathrm{CO}_{2}, \mathrm{CO}$ и $\mathrm{H}_{2}$ в газовой смеси повышаются до $0,1 \%, 20 \%$ и 7,4 \%. Соответственно величина $R_{\mathrm{H}_{2} \mathrm{O}}$ уменьшается с $59,25 \%$ до 43,6 $\%$, значение $R_{\mathrm{O}_{2}}$ падает с $40,75 \%$ до $28 \%$ (рис. $2 a$, рис. 4, рис. 5, кривые 2).

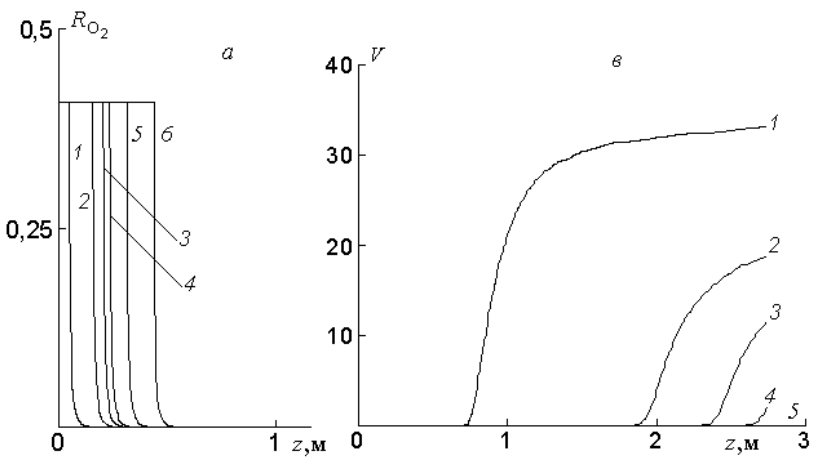

Рис. 2. Распределение объемной доли кислорода (a) и летучих веществ (в) по высоте неподвижного слоя в зависимости от времени при отношении массовых долей в парокислородной смеси $\mathrm{H}_{2} \mathrm{O} / \mathrm{O}_{2}=\mathbf{4 5 / 5 5}: 1-60 \mathrm{c} ; 2-200 \mathrm{c}$; $3-260$ c; $4-300 \mathrm{c} ; 5-400 \mathrm{c} ; 6-560$ c.

Fig. 2. Distribution of the volume fraction of oxygen $(a)$ and volatile substances ( $b$ ) over the height of the fixed bed as a function of time with respect to the mass fractions in the steam-oxygen mixture $\mathbf{H}_{2} \mathbf{O} / \mathbf{O}_{2}=\mathbf{4 5 / 5 5}: 1-60 \mathrm{~s} ; 2-200 \mathrm{~s} ; 3-$ $260 \mathrm{~s} ; 4-300 \mathrm{~s} ; 5-400 \mathrm{~s} ; 6-560 \mathrm{~s}$.
В этом интервале происходит резкое убывание функции $\delta(\tau, z)$ из-за конверсии коксозольных частиц за счет гетерогенных реакций (см. (1)), благодаря чему диаметр дискретной фазы уменьшается с $\delta=4,39$ мм до минимального размера частиц $\delta_{\text {ash }}=3,96$ мм, состоящих из золы (рис. 6, кривая 2). Полученный таким образом инертный материал формирует шлаковую подушку, которая защищает колосники (поз. 2 (рис. 1)) от перегрева.

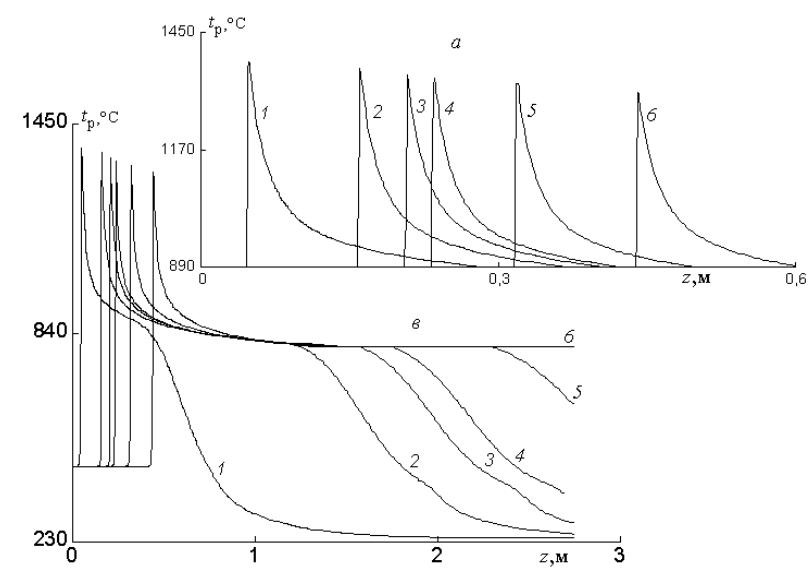

Рис. 3. Распределение температуры частиц по высоте неподвижного слоя в зависимости от времени при отношении массовых долей в парокислородной смеси $\mathrm{H}_{2} \mathrm{O} / \mathrm{O}_{2}$ $=$ 45/55 (обозначения те же, что на рис. 2 ).

Fig. 3. Temperature distribution of particles along the height of the fixed bed as a function of time with the ratio of mass fractions in the steam-oxygen mixture $\mathrm{H}_{2} \mathrm{O} / \mathrm{O}_{2}=45 / 55$ (notations are the same as in Fig. 2).
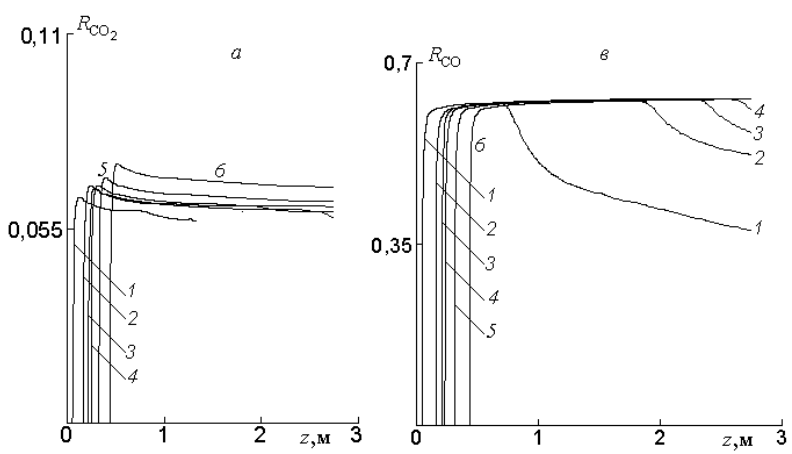

Рис. 4. Распределение объемных долей компонентов газа $\mathrm{CO}_{2}$ (a) и $\mathrm{CO}$ (в) по высоте неподвижного слоя в зависимости от времени при отношении массовых долей в парокислородной смеси $\mathrm{H}_{2} \mathrm{O} / \mathrm{O}_{2}=45 / 55$ (обозначения те же, что на рис. 2).

Fig. 4. The distribution of the volume fractions of the components of the gas $\mathrm{CO}_{2}(a)$ and $\mathrm{CO}(\boldsymbol{s})$ over the height of the fixed bed as a function of time with respect to the mass fractions in the steam-oxygen mixture $\mathrm{H}_{2} \mathrm{O} / \mathrm{O}_{2}=45 / 55$ (notations are the same as in Fig. 2). 


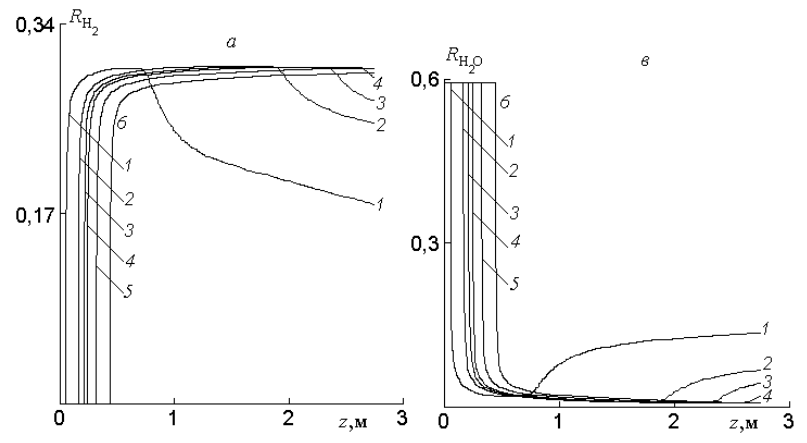

Рис. 5. Распределение объемных долей компонентов газа $\mathrm{H}_{2}\left(\right.$ a) и $\mathrm{H}_{2} \mathrm{O}$ (в) по высоте неподвижного слоя в зависимости от времени при отношении массовых долей в парокислородной смеси $\mathrm{H}_{2} \mathrm{O} / \mathrm{O}_{2}=45 / 55$ (обозначения те же, что на рис. 2).

Fig. 5. Distribution of the volume fractions of the components of the gas $\mathrm{H}_{2}(a)$ and $\mathrm{H}_{2} \mathrm{O}(b)$ over the height of the fixed bed depending on the time with respect to the mass fractions in the steam-oxygen mixture $\mathrm{H}_{2} \mathrm{O} / \mathrm{O}_{2}=45 / 55$ (notations are the same as in Fig. 2).

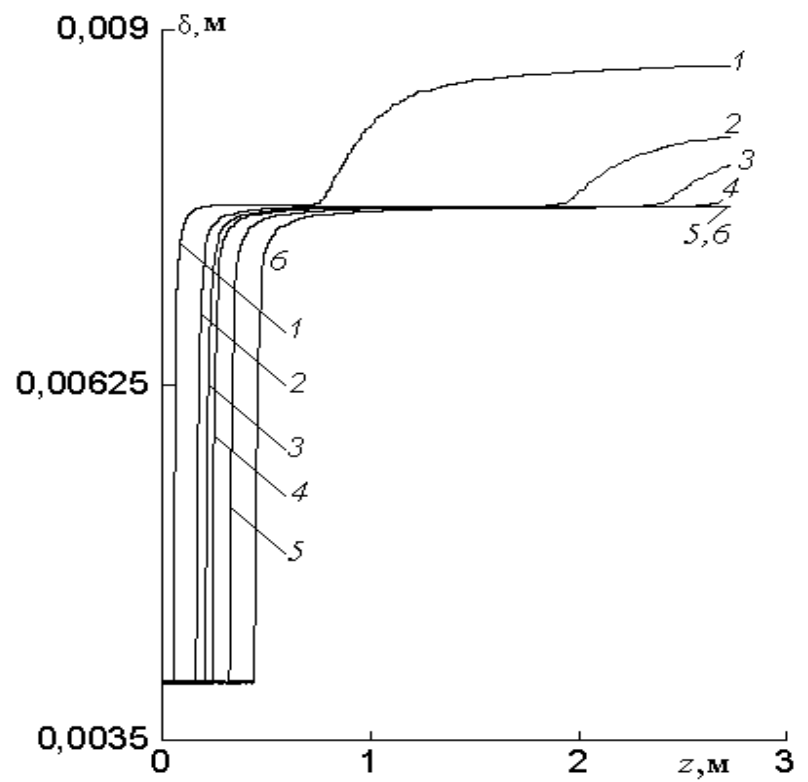

Рис. 6. Распределение диаметра частиц по высоте неподвижного слоя в зависимости от времени при отношении массовых долей в парокислородной смеси $\mathrm{H}_{2} \mathrm{O} / \mathrm{O}_{2}=45 / 55$ (обозначения те же, что на рис. 2).

Fig. 6. The distribution of the diameter of the particles at the height of the fixed bed depending on the time with respect to mass fractions in the steam-oxygen mixture $\mathrm{H}_{2} \mathrm{O} / \mathrm{O}_{2}=45 / 55$ (notations are the same as in Fig. 2).

На втором участке (окислительновосстановительная область реагирования) 0,161 м $<z<0,25$ м теплопоглощение эндотермических реакций превосходит тепловыделение экзотермических реакций. В результате значения $t_{\mathrm{p}}$ и $R_{\mathrm{H}_{2} \mathrm{O}}$ снижаются до $945^{\circ} \mathrm{C}$ и $4,7 \%$, объемные доли $\mathrm{CO}_{2}$, $\mathrm{CO}$ и $\mathrm{H}_{2}$ продолжают возрастать и достигают величин $6,7 \%, 60,7 \%$ и $27,9 \%$ соответственно, а диаметр частиц уменьшается с 7,5 мм до 4,39 мм.

Бескислородная область $0,25 \mathrm{~m}<z<1,9 \mathrm{M}$ характеризуется относительно низкими значениями температур $410-945{ }^{\circ} \mathrm{C}$ и объемным содержанием в газе $\mathrm{CO}_{2} 6,14-6,7 \%$ и $\mathrm{H}_{2} \mathrm{O}$ 1,36-4,7 \%, что приводит к существенному снижению скоростей восстановительных реакций $\mathrm{C}+\mathrm{CO}_{2}=2 \mathrm{CO}$ и $\mathrm{C}+\mathrm{H}_{2} \mathrm{O}=\mathrm{CO}+\mathrm{H}_{2}$, поэтому концентрации газовых компонентов $\mathrm{CO}, \mathrm{H}_{2}$ и размер частиц мало изменяются в этом диапазоне.

Конвективный теплообмен между твердой и газовой фазами и тепловыделение гомогенных химических реакций $\mathrm{CO}+0,5 \mathrm{O}_{2}=\mathrm{CO}_{2}$ и $\mathrm{H}_{2}+0,5 \mathrm{O}_{2}=\mathrm{H}_{2} \mathrm{O}$ обеспечивают резкое возрастание кривой $t_{\mathrm{g}}(\tau, z)$ с $450{ }^{\circ} \mathrm{C}$ до максимального значения $995{ }^{\circ} \mathrm{C}$ (рис. 7, кривая 2). Из рис. 3 и 7 видно, что зависимости $t_{\mathrm{p}}(\tau, z)$ и $t_{\mathrm{g}}(\tau, z)$ подобны, однако максимум кривой $t_{\mathrm{g}}(\tau, z)$ смещен относительно максимума функции $t_{\mathrm{p}}(\tau, z)$ из первой зоны в окислительно-восстановительную область реагирования.

В зоне сухой перегонки 1,9 м $<z<2,75$ м (поз. 5 (рис. 1)) происходит нагрев высушенной дробленки до температуры $240-410{ }^{\circ} \mathrm{C}$ (рис. 3 , кривая 2) за счет межфазного конвективного теплообмена и радиационно-кондуктивного теплопереноса твердой фазы, что обеспечивает интенсивный выход летучих веществ из угольных частиц.

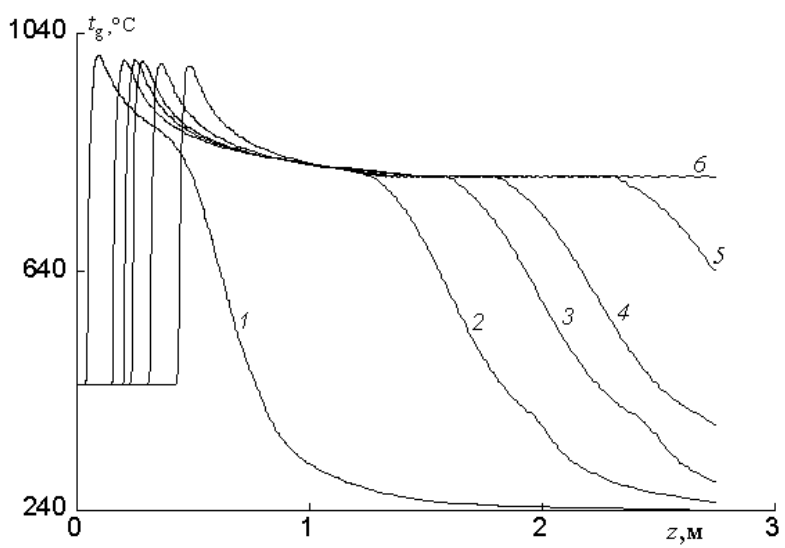

Рис. 7. Распределение температуры газа по высоте неподвижного слоя в зависимости от времени при отношении массовых долей в парокислородной смеси $\mathrm{H}_{2} \mathrm{O} / \mathrm{O}_{2}=45 / 55$ (обозначения те же, что на рис. 2).

Fig. 7. Gas temperature distribution over the height of the fixed bed as a function of time with respect to the mass fractions in the steam-oxygen mixture $\mathrm{H}_{2} \mathrm{O} / \mathrm{O}_{2}=\mathbf{4 5 / 5 5}$ (notations are the same as in Fig. 2).

В модели летучие шубаркольского каменного длиннопламенного угля представлены в виде кислородосодержащего соединения, которое при нагреве разлагается на компоненты пиролизного газа согласно реакции $\mathrm{CH}_{3,147} \mathrm{O}_{0,5625} \rightarrow 0,09132 \mathrm{CO}+$ $+0,0581 \mathrm{CO}_{2}+0,5042 \mathrm{CH}_{4}+0,05783 \mathrm{C}_{6} \mathrm{H}_{6}+0,03655 \mathrm{H}_{2}+$ $+0,3549 \mathrm{H}_{2} \mathrm{O}$. Из этой реакции следует, что объ- 
емные доли метана и водяного пара значительно больше, чем диоксида углерода, окиси углерода и водорода. Поэтому при смешении компонентов летучих веществ с компонентами газа, выходящего из зоны газификации поз. 4 (рис. 1), происходит уменьшение величин $R_{\mathrm{CO}}, R_{\mathrm{H}_{2}}$ и возрастание значений $R_{\mathrm{H}_{2} \mathrm{O}}, R_{\mathrm{CH}_{4}}$ и $R_{\mathrm{C}_{6} \mathrm{H}_{6}}$ (рис. 4 в, рис. 5 , рис. 8 , кривые 2 ). В пиролизной зоне за счет выхода летучих веществ наблюдается уменьшение диаметра частиц с 8,2 мм до 7,64 мм (первый член уравнения (11); рис. 6, кривая 2).

$\mathrm{C}$ течением времени высота шлаковой подушки возрастает $\left(\Delta z_{\text {ash }}(\tau=60 \mathrm{c})=47,3 \mathrm{MM}, \Delta z_{\mathrm{ash}}(\tau\right.$ $=560 \mathrm{c})=438,3$ мм), вследствие чего зоны окисления, газификации и пиролиза смещаются вверх по вертикальной оси $z$ (рис. 2-8, ср. кривые 1 и б). Следует отметить, что выгорания компонентов пиролизных газов $\mathrm{C}_{6} \mathrm{H}_{6}, \mathrm{CH}_{4}$ и кислородосодержащего соединения $\mathrm{CH}_{3,147} \mathrm{O}_{0,5625}$ не происходит, так как скорость убывания летучих веществ по высоте слоя значительно выше, чем скорость перемещения окислительной зоны. Например, при $\tau=260$ с зона окисления располагается на участке 0,21 м $<z<0,25$ м, в то время как область содержания летучих веществ находится в диапазоне 2,188 м $<z<2,75$ м (рис. 2, кривые 3).

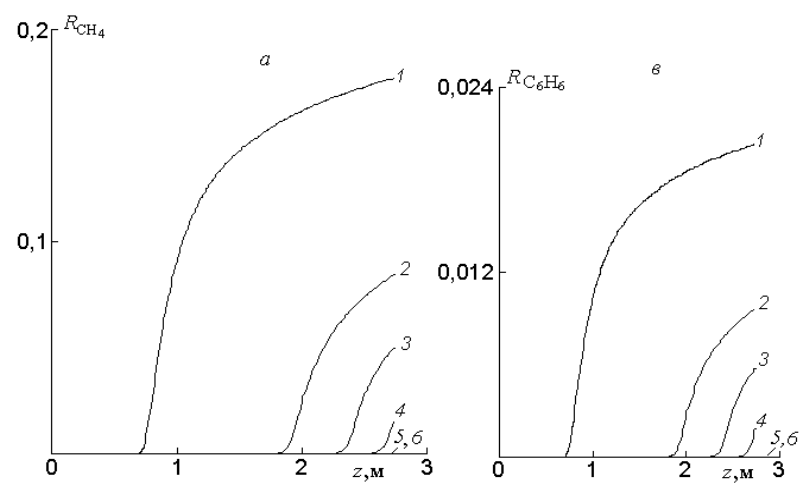

Рис. 8. Распределение объемных долей компонентов газа $\mathrm{CH}_{4}(a)$ и $\mathrm{C}_{6} \mathrm{H}_{6}($ в) по высоте неподвижного слоя в зависимости от времени при отношении массовых долей в парокислородной смеси $\mathrm{H}_{2} \mathrm{O} / \mathrm{O}_{2}=\mathbf{4 5} / 55$ (обозначения те же, что на рис. 2).

Fig. 8. Distribution of the volume fractions of the components of the gas $\mathrm{CH}_{4}(a)$ and $\mathrm{C}_{6} \mathrm{H}_{6}(b)$ over the height of the fixed bed as a function of time with respect to the mass fractions in the steam-oxygen mixture $\mathrm{H}_{2} \mathrm{O} / \mathrm{O}_{2}=45 / 55$ (notations are the same as in Fig. 2).

По этой причине скорость распада комплекса $r_{\mathrm{CH}_{3,14} \mathrm{O}_{0,5625} \rightarrow}$ (см. табл. 1) была повышена за счет уменьшения энергии активации с $108 \cdot 10^{3}$ до $60 \cdot 10^{3}$ кДж/кмоль. В результате более $99 \%$ комплекса $\mathrm{CH}_{3,147} \mathrm{O}_{0,5625}$ распадается на газовые компоненты $\mathrm{CO}, \mathrm{CO}_{2}, \mathrm{CH}_{4}, \mathrm{C}_{6} \mathrm{H}_{6}, \mathrm{H}_{2}$ и $\mathrm{H}_{2} \mathrm{O}$ и менее $1 \%$ остается в виде соединения $\mathrm{CH}_{3,147} \mathrm{O}_{0,5625}$.
Во временном интервале $0<\tau<350$ с состав генераторного газа на выходе из реактора изменяется. При $\tau=60$ с (на сухую массу):

$$
R_{\mathrm{CO}}=40,82 \%, R_{\mathrm{H}_{2}}=19,3 \%, R_{\mathrm{CO}_{2}}=15,3 \% \text {, }
$$

$R_{\mathrm{CH}_{4}}=22 \%$ и $R_{\mathrm{C}_{6} \mathrm{H}_{6}}=2,53 \% ; \tau=260$ с: $R_{\mathrm{CO}}=$ $=58,36 \%, R_{\mathrm{H}_{2}}=28 \%, R_{\mathrm{CO}_{2}}=6,4 \%, R_{\mathrm{CH}_{4}}=6,4 \%$ и $R_{\mathrm{C}_{6} \mathrm{H}_{6}}=0,75 \%, \mathrm{H}_{2} / \mathrm{CO}=0,48$. Расчетный состав газа при $\tau=260$ с хорошо согласуется с литературными данными, приведенными в [8]: $R_{\mathrm{CO}}=58 \%, R_{\mathrm{H}_{2}}=30 \%, R_{\mathrm{CO}_{2}}=5 \%, R_{\mathrm{CH}_{4}}=6,9 \%$, $\mathrm{H}_{2} / \mathrm{CO}=0,52$.

Диапазон $\tau>350$ с характеризуется отсутствием летучих веществ в угольных частицах по всей высоте неподвижного слоя (рис. 2 в, кривая 5). Поэтому с течением времени при интенсивном перемещении границ зон окисления, газификации и пиролиза по вертикальной оси $z$ состав генераторного газа на выходе из реактора практически не изменяется: $R_{\mathrm{CO}}=61,3 \%, R_{\mathrm{H}_{2}}=30,13 \%$, $R_{\mathrm{CO}_{2}}=7,68 \%, R_{\mathrm{CH}_{4}}=0$ и $R_{\mathrm{C}_{6} \mathrm{H}_{6}}=0$ (рис. 4 , рис. 5 $a$, рис. 8 , ср. кривые 5 и 6 ).

При организации процесса газификации шубаркольского каменного длиннопламенного угля в газогенераторе необходимо решить две проблемы. Первая из них связана с низкой зольностью исходного топлива $\mathrm{A}^{\mathrm{r}}=8,55 \%$ (согласно сертификату). Как отмечается в роботе [9], величина $\mathrm{A}^{\mathrm{r}}$ в реальных условиях может снижаться до $3 \%$. Это приводит к значительному уменьшению высоты шлаковой подушки, тем самым приближает диапазон максимальных тепловых потоков к колосниковой решетке, что усиливает ее перегрев (рис. 3, кривая 1). Вторая задача связана с низкой температурой начала шлакования $t_{\text {slag }}=$ $1003^{\circ} \mathrm{C}$, которая вычислялась по химическому составу золы, приведенному в сертификате. Величина $t_{\text {slag }}$ оказывается ниже, чем температура начала деформации золы $t_{\mathrm{A}}=1100^{\circ} \mathrm{C}$. Из рис. 3 следует, что максимальная температура частиц при $\tau=60$ с составляет $1371^{\circ} \mathrm{C}$. Значение $t_{\mathrm{p}, \max }$

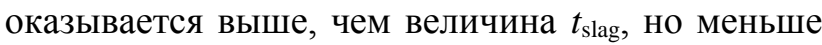
температуры жидкоплавкого состояния золы $t_{\mathrm{C}}=1440{ }^{\circ} \mathrm{C}$, что говорит о возможном формировании агломератов и шлаковании в области, прилегающей к колосниковой решетке, вследствие чего могут возникнуть проблемы с эксплуатацией газогенератора. Если испытания на действующей промышленной установке покажут наличие серьезных проблем, тогда целесообразно рассмотреть организацию двух альтернативных режимов работы установки. Первый из них характеризуется повышением максимальной темпера- 
туры частиц в зоне максимальных тепловыделений с $1371{ }^{\circ} \mathrm{C}$ до $1550{ }^{\circ} \mathrm{C}$ за счет уменьшения отношения массовых долей в парокислородной смеси $\mathrm{H}_{2} \mathrm{O} / \mathrm{O}_{2}$ с 45/55 до 40/60 (рис. 3, рис. 9, кривые 1 ). Высокий уровень температур $t_{\mathrm{p}, \max }>t_{\mathrm{C}}$ в узкой области, прилегающей к поду реактора, обеспечивает устойчивое жидкое шлакоудаление из газогенератора. На выходе из реактора получается следующий состав генераторного газа на сухую массу. При $\tau=280$ с: $R_{\mathrm{CO}}=65 \%$, $R_{\mathrm{H}_{2}}=25,6 \%, R_{\mathrm{CO}_{2}}=3,8 \%, R_{\mathrm{CH}_{4}}=5 \%$ и $R_{\mathrm{C}_{6} \mathrm{H}_{6}}=$ $=0,57 \% ; \tau=330 \mathrm{c}: R_{\mathrm{CO}}=69 \%, R_{\mathrm{H}_{2}}=27 \%$, $R_{\mathrm{CO}_{2}}=3,6 \%, R_{\mathrm{CH}_{4}}=0,065 \%$ и $R_{\mathrm{C}_{6} \mathrm{H}_{6}}=0$. Эти результаты хорошо согласуются с литературными данными, приведенными в [10]. Из состава генераторного газа следует, что его калорийность выше, чем при газификации угольной пыли в потоке [11].

Второй режим базируется на твердом шлакоудалении, когда значение $t_{\mathrm{p}}$ в окислительной зоне не превышает $1000{ }^{\circ} \mathrm{C}$. Для построения этого режима необходимо устранить перегрев колосниковой решетки за счет добавления инерта (отработанной золы) в исходное топливо, что позволит повысить высоту шлаковой подушки и тем самым стабилизировать тепловое состояние решетки. Детальный анализ второго режима будет представлен во второй части статьи.

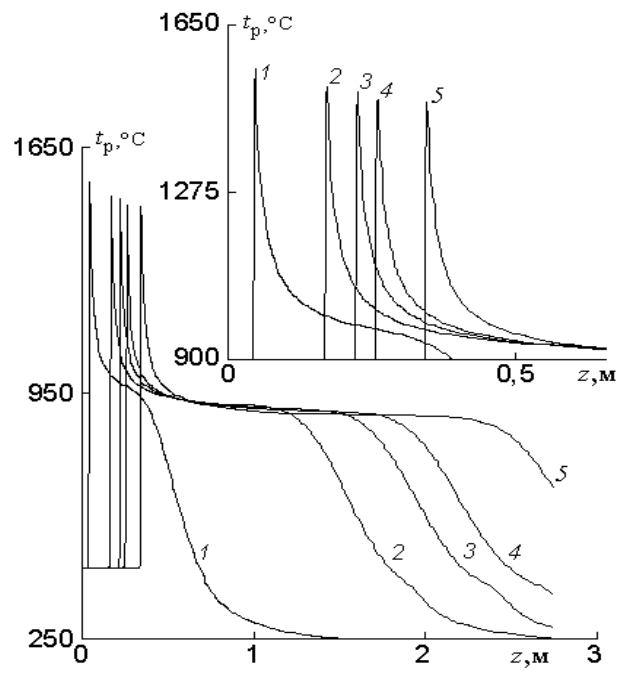

Рис. 9. Распределение температуры частиц по высоте неподвижного слоя в зависимости от времени при отношении массовых долей в парокислородной смеси $\mathrm{H}_{2} \mathrm{O} / \mathrm{O}_{2}$ $=40 / 60$ (обозначения те же, что на рис. 2 ).

Fig. 9. Temperature distribution of particles along the height of the fixed bed as a function of time with the ratio of mass fractions in the steam-oxygen mixture $\mathrm{H}_{2} \mathrm{O} / \mathrm{O}_{2}=40 / 60$ (notations are the same as in Fig. 2)/

Выводы. 1. Предложенная модель позволяет получить детальную информацию о геометрических, аэродинамических, тепловых и физико- химических параметрах парокислородной газификации твердого топлива под давлением в неподвижном слое в любой момент времени. Эта информация может быть использована при конструировании реакторов на стадиях эскизного, технического и рабочего проектирования, пусконаладочных режимах и работе газогенератора на различных нагрузках, когда процесс парокислородной газификации угля является нестационарным из-за цикличности подачи исходного топлива и выгрузки золы при помощи системы шлюзовых бункеров.

2. Показано, что:

a) участок окислительной зоны, где температура угольных частиц шубаркольского каменного длиннопламенного угля достигает максимального значения, очень узок и составляет 10-11 мм;

б) основной процесс газификации коксозольных частиц протекает на малом окислительновосстановительном участке фиксированного слоя $\Delta z_{\text {bed }}=89$ мм, что приводит к понижению температуры твердой фазы на $420{ }^{\circ} \mathrm{C}$ и объемной доли $\mathrm{H}_{2} \mathrm{O}$ до $4,7 \%$, вследствие чего оставшаяся часть интервала газификации $\Delta z_{\text {bed }}=1,65$ м является малоэффективной;

в) кислородная и восстановительная зоны не содержат пиролизных газов, так как скорость убывания летучих веществ по высоте слоя значительно выше, чем скорость перемещения указанных диапазонов;

г) в диапазоне $0<\tau<350$ с состав генераторного газа на выходе из реактора изменяется из-за интенсивного выхода летучих веществ из угольных частиц в зоне сухой перегонки в отличие от интервала $\tau>350$, где отсутствует участок сухой перегонки, благодаря чему состав уходящих газов с течением времени не изменяется;

д) при $\tau=260$ с состав генераторного газа (на сухую массу): $R_{\mathrm{CO}}=58,36 \%, R_{\mathrm{H}_{2}}=28 \%, R_{\mathrm{CO}_{2}}=$ $=6,4 \%, R_{\mathrm{CH}_{4}}=6,4 \%$ и $R_{\mathrm{C}_{6} \mathrm{H}_{6}}=0,75 \%$ хорошо согласуется с литературными данными, приведенными в работе [8]: $R_{\mathrm{CO}}=58 \%, R_{\mathrm{H}_{2}}=30 \%$, $R_{\mathrm{CO}_{2}}=5 \%, R_{\mathrm{CH}_{4}}=6,9 \%$.

3. Предложены два альтернативных режима работы газогенератора. Первый из них связан с повышением максимальной температуры частиц в малой области, прилегающей к поду реактора, с $1371{ }^{\circ} \mathrm{C}$ до $1550{ }^{\circ} \mathrm{C}$, что позволяет организовать устойчивое жидкое шлакоудаление из газогенератора. Второй режим основан на твердом шлакоудалении, когда температура частиц не превышает $1000{ }^{\circ} \mathrm{C}$. В этом случае для устранения перегрева колосниковой решетки в исходное топливо добавляется отработанная зола, что позволяет повысить 
высоту шлаковой подушки и тем самым стабилизировать тепловое состояние решетки.

1. Аэров М. Э., Тодес О. М., Наринский Д. А. Аппараты со стационарным зернистым слоем. Л. Химия. $1979.176 \mathrm{c}$.

2. Rokhman B.B. Modeling and numerical investigation of the process of vapor-oxygen gasification of solid fuels in a vertical flow reactor under pressure. Journal of Ehgineering Physics and Thermopysics. 2014. Vol. 87. No. 5. Pp. 1103-1115.

3. Westbrook C.K. Dryer F.L. Simplified reaction mechanisms for the oxidation of hydrocarbon fuels in flames. Combust. Sci. Technol. 1981. Vol. 27. Pp. 31-43.

4. Bustanmante F. Enick R.M. Killmeyer R.P. Howard B.H. Rothenberger K.S. Cugini A.V. Morreale B.D. Ciocco M.V. Uncatalyzed and wall-catalyzed forward water-gas shift reaction kinetics. AIChE J. 2005. Vol. 51. Pp. 1440-1454.

5. Ma J., Zitney S.E. CFD modeling of entrained-flow gasifiers with improved physical and chemical submodels. Energy Fuels 2012. Vol. 26. Pp. 7195-7219.

6. Gómes-Barea A., Leckner B. Modeling of biomass gasification in fluidized bed. Progress in Energy and Combustion Science. 2010. Vol. 36. Pp. 449-509.

7. Wen C.Y., Chaung T.Z. Entrainment Coal Gasification Modeling. Ind. Eng. Chem. Process Des. Dev. 1979. Vol. 18. № 4. Pp. 684-695.

8. Gräbner M. Industrial Coal Gasification Technologies Covering Baseline and High Ash Coal. Wiley. 2014. 384 p.

9. Нагорнов А.Н. Исследование и разработка технологии газификации малозольных углей в плотном слое под давлением при паровоздушном дутье. Автореферат диссертации на соискание ученой степени кандидата технических наук. Барнаул. 2010. 20 с.

10. Yoon H., Wei J., Denn M. A model for moving bed coal gasification reactors. AIChE J. 1978. Vol. 24. №. 5. Pp. 885-903.

11. Рохман Б.Б. Моделирование тепломассообмена и химического реагирования газодисперсного потока пылевидных частиц угля в высокотемпературном газификаторе Відновлювана енергетика. 2016. № 3. С. 13-26.

\section{ДВОВИМІРНА МОДЕЛЬ ПРОЦЕСУ ГАЗИФІКАЦІЇ ТВЕРДОГО ПАЛИВА В НЕРУХОМОМУ ШАРІ ПІД ТИСКОМ. 1. ДОСЛІДЖЕННЯ КОНВЕРСІЇ ШУБАР- КОЛЬСЬКОГО КАМ'ЯНОГО ВУГІЛЛЯ В ПАРОКИС- НЕВІЙ СУМІШІ ПРИ СПІВВІДНОШЕННІ МАСОВИХ ЧАСТОК $\mathrm{H}_{2} \mathrm{O} / \mathrm{O}_{2}=45 / 55$}

Б.Б. Рохман, доктор технічних наук

Інститут вугольних енерготехнологій НАН України 04070 м. Київ, вул. Андріївська, 19

Побудовано нестаціонарну модель проиесу парокисневої газифікації твердого палива в фіксованому шарі під тиском з урахуванням міжфазного конвективного теплообміну, радіаційно-кондуктивного теплопереносу твердої фази, радіаційного і кондуктивного теплообміну шару зі стінкою реактора, гетерогенних і гомогенних хімічних реакиій, сил тяжіння і аеродинамічного опору. Отримано розподіл температур фаз, діаметрів вугільних частинок, концентрацій газових компонентів по висоті шару в залежності від часу при газифікаиії шубаркольского кам'яного довгополуменевого вугілля під тиском 3 МПа при співвідноченні масових часток в парокисневій суміші $\mathrm{H}_{2} \mathrm{O} / \mathrm{O}_{2}=45 / 55$. Отримана інформація може бути використана при конструюванні реакторів, пуско-налагоджувальних режимах і роботі газо- генератора на різних навантаженнях, коли процес парокисневої газифікації вугілля є нестацуіонарнм через цуиклічність подачі вихідного палива і вивантаження золи за допомогою використання системи илюзових бункерів. Показано, щуо ділянка окислювальної зони, де температура вугільних частинок досягає максимального значення, дуже вузька і становить 10-11 мм. Запропоновано два альтернативних режими роботи газогенератора. Перший з них $\mathrm{H}_{2} \mathrm{O} / \mathrm{O}_{2}=40 / 60$ пов'язаний з підвищенням максимальної температури частинок в області, прилеглій до поду реактора до $1550{ }^{\circ} \mathrm{C}$, ио дозволяє організувати стійке рідке шлаковидалення з газогенератора. Другий режим $\mathrm{H}_{2} \mathrm{O} / \mathrm{O}_{2}=72 / 28$ базується на твердому илаковидаленні, коли температура частинок не перевишує $1000^{\circ} \mathrm{C}$. Бібл.11, табл.1, рис.9.

Ключеві слова: нерухомий шар, вугілля, теплопроводність, парокиснева газифікація, кондуктивний, радиаџіоний, темnература

\section{REFERENCES}

1. Aerov M. E., Todes O. M., Narinskiy D. Apparatyi so statsionarnyim zernistyim sloem. [Apparatus with a stationary granular bed]. Leningrad. USSR. Khimiya. 1979. 176 p. [in Russian].

2. Rokhman B.B. Modeling and numerical investigation of the process of vapor-oxygen gasification of solid fuels in a vertical flow reactor under pressure. Journal of Ehgineering Physics and Thermopysics. 2014. Vol. 87. No. 5. Pp. 1103-1115. [in English].

3. Westbrook C.K., Dryer F.L. Simplified reaction mechanisms for the oxidation of hydrocarbon fuels in flames. Combust. Sci. Technol.. 1981. No. 27. Pp. 31-43. [in English].

4. Bustanmante F., Enick R.M, Killmeyer R.P, Howard B.H, Rothenberger K.S, Cugini A.V, Morreale B.D., Ciocco M.V. Uncatalyzed and wall-catalyzed forward water-gas shift reaction kinetics. AIChE J. 2005. No. 51. Pp. 1440-1454. [in English].

5. Ma J., Zitney S.E. CFD modeling of entrained-flow gasifiers with improved physical and chemical submodels. Energy Fuels. 2012. No. 26. Pp. 7195-7219. [in English].

6. Gómes-Barea A., Leckner B. Modeling of biomass gasification in fluidized bed. Progress in Energy and Combustion Science. 2010. No. 36. Pp. 449-509. [in English].

7. Wen C. Y., Chaung T. Z. Entrainment Coal Gasification Modeling. Ind. Eng. Chem. Process Des. Dev.. 1979. Vol. 18. No. 4. Pp. 684-695. [in English].

8. Gräbner M. Industrial Coal Gasification Technologies Covering Baseline and High- Ash Coal. Wiley. 2014. 384 p. [in English].

9. Nagornov A. N. Issledovanie i razrabotka tehnologii gazifikacii malozolnyh uglej $\mathrm{v}$ plotnom sloe pod davleniem pri parovozdushnom dute. Avtoreferat dissertacii na soiskanie uchenoj stepeni kandidata tehnicheskih nauk. [Research and development of technology for gasification of low-ash coals in a dense bed under pressure with a vapor-air blast. Abstract of thesis for the degree of candidate of technical sciences]. Barnaul. Russia. 2010. 20 p. [in Russian].

10. Yoon H., Wei J., Denn M. A model for moving bed coal gasification reactors. AIChE J. 1978. Vol. 24. No. 5. Pp. 885903. [in English].

11. Rokhman B.B. Modelirovanie teplomassoobmena i himicheskogo reagirovaniya gazodispersnogo potoka pylevidnyh chastic uglya $\mathrm{v}$ vysokotemperaturnom gazifikatore. [Modelling heat-and-mass transfer and chemical reaction of the gas-dispersed flow of the pulverized coal particles in a high-temperature gasifier]. Vidnovluvana energetika, 2016. No. 3. 13-26. [in Russian].

Стаття надійшла до редакції 20.11.18 Остаточна версія 12.03.19 